\title{
Neutrophil-to-Lymphocyte Ratio Predicts Survival After Whole-brain Radiotherapy in Non-small Cell Lung Cancer
}

\author{
HIROSHI DOI, KIYOSHI NAKAMATSU, SHIMPEI ANAMI, KOHEI FUKUDA, MASAHIRO INADA, \\ HITOSHI TATEBE, KAZUKI ISHIKAWA, SHUICHI KANAMORI, HAJIME MONZEN and YASUMASA NISHIMURA
}

Department of Radiation Oncology, Kindai University Faculty of Medicine, Osaka-Sayama, Japan

\begin{abstract}
Aim: This study aimed to identify prognostic factors for response to whole-brain radiotherapy (WBRT) in patients with brain metastases (BMs) from non-small cell lung cancer (NSCLC). Patients and Methods: This study retrospectively evaluated 100 patients who underwent WBRT for BMs from NSCLC between December 2012 and October 2017. Clinical factors were tested for associations with overall survival after WBRT. Results: The median follow-up time was 134 days (range=14-1,395 days), the median survival time was 143 days, and the 1-year survival rate was $30.4 \%$. Univariate and multivariate analyses revealed that better survival was independently associated with expression of programmed death-ligand 1 (PD-L1), no previous treatment for BMs, no extracranial disease, and a neutrophil-to-lymphocyte ratio (NLR) of <5.0. Conclusion: A low NLR and positive PD-L1 expression independently predict better prognosis in patients with BMs from NSCLC after WBRT. These findings suggest that the potential immune response may influence survival among patients with BMs.
\end{abstract}

The lung is the most common primary site for brain metastases (BMs), which affect up to $30 \%$ of patients with lung cancer (1). There are several models for predicting the prognosis of patients with BMs, such as the Radiation Therapy Oncology Group-Recursive Partitioning Analysis (RTOG-RPA) and the Graded Prognostic Assessment (GPA) $(2,3)$. In addition, a recent report has indicated that gene mutation status can help predict outcomes after radiosurgery for patients with multiple BMs (4). However, patients who are candidates for whole-brain

This article is freely accessible online.

Correspondence to: Hiroshi Doi, MD, Ph.D., Department of Radiation Oncology, Kindai University Faculty of Medicine, 377-2, Ohno-higashi, Osaka-Sayama, Osaka, Japan. Tel: +81 723660221, Fax: +81 723682388, e-mail: h-doi@med.kindai.ac.jp

Key Words: Neutrophil-to-lymphocyte ratio, lung cancer, immunotherapy, brain metastasis, whole-brain radiotherapy. radiotherapy (WBRT) are thought to have unfavorable prognoses, despite the absence of clear prognostic factors. In this context, WBRT is a standard palliative treatment for patients with BMs who are unsuitable for surgical resection or stereotactic radiosurgery/radiotherapy (SRS/SRT) (5), although it reportedly provides a limited clinical benefit (6). Therefore, it can be difficult to use the RPA or GPA prognostic models for patients who are undergoing WBRT, as these models incorporate extracranial metastasis status and number of BMs.

Immune checkpoint inhibitors have significantly improved survival outcomes among patients with recurrent and refractory non-small cell lung cancer (NSCLC) $(7,8)$. In addition, pre-clinical and clinical studies have indicated that immunotherapy and radiotherapy have synergistic effects, with a high possibility of abscopal effects, which may significantly alter the current treatment strategies for metastatic diseases (9). Furthermore, Shaverdian et al. recently reported that previous radiotherapy may prolong overall survival among patients who are receiving programmed death-1 (PD-1) blockade for advanced NSCLC covered with patients who had not previously undergone radiotherapy (10). Thus, WBRT might be useful for both intracranial tumor control and improving the immune response to systemic disease. However, there are no clear prognostic factors for WBRT, especially among patients with BMs. Therefore, the present study aimed to identify prognostic factors for response to radiotherapy among patients with BMs from NSCLC, especially in terms of their potential immune response.

\section{Patients and Methods}

Patients. This retrospective study was approved by our Institutional Review Board (reference number 30-028), and all patients had provided informed consent for WBRT. Between December 2012 and October 2017, consecutive patients with BMs who underwent WBRT at our Institution were identified. Two patients who had follow-up durations of less than 6 months without any specific events were excluded. All patients had pathologically confirmed NSCLC and a diagnosis of BMs based on computed tomography or magnetic resonance imaging findings. Blood test data from between 
4 weeks before WBRT and the first day of the WBRT course were available for all but three patients, with one patient having completed the testing on the second day of the WBRT course, another patient having completed the testing 3 months before the WBRT, and the last patient having serum lactate dehydrogenase (LDH) data that were acquired 2 months before WBRT. These patients were all included in the present study because there were no clinical findings that might have affected results.

All patients were treated using conventional external beam radiotherapy with a typical photon energy of 4-6 MV and opposed lateral treatment fields that encompassed the entire brain. The prescribed dose was calculated at the isocenter of the radiation fields based on daily treatments. Two of the included patients received a dose of $30 \mathrm{~Gy}$ in 12 fractions followed by $15 \mathrm{~Gy}$ in six fractions for the gross tumor volume (total of $45 \mathrm{~Gy}$ in 18 fractions), and one patient received a dose of 35 Gy in 14 fractions followed by $5 \mathrm{~Gy}$ in two fractions for the gross tumor volume (total of $40 \mathrm{~Gy}$ in 16 fractions). No patients underwent planned WBRT combined with SRS/SRT.

Statistical analysis. Data are reported as median (range) or number (percentage). Time-to-event analyses were performed from the start of radiotherapy to the emergence of the event. The Kaplan-Meier method and log-rank test were used to compare the curves for cumulative intracranial disease control and overall survival. Potential prognostic factors were evaluated using the Cox proportional hazards model, and the results are reported as hazard ratios (HRs) and corresponding 95\% confidence intervals (CIs). Factors with $p$-values of less than 0.2 in the univariate analyses were included in the multivariate model. All analyses were performed using JMP software (version 12.2.0; SAS Institute, Cary, NC, USA), and differences were considered statistically significant at $p$-values of less than 0.05 .

\section{Results}

The patients' characteristics are shown in Table I. The median follow-up time was 134 days (range=14-1,423 days). The survival curves are shown in Figure 1. Among the 66 patients $(66 \%)$ with symptomatic BMs, 39 (59\%) experienced symptom improvement after WBRT. Eightyseven patients $(87 \%)$ died during the follow-up (Table I). Six out of seven patients with programmed death-ligand 1 (PDL1) overexpression received anti-PD-1 therapy. No grade 3 or greater toxicities were observed.

The results of the univariate and multivariate analyses are shown in Table II. Univariate analyses revealed that better survival was associated with an Eastern Cooperative Oncology Group performance status (ECOG-PS) of 0-1, adenocarcinoma pathology, PD-L1 expression, no history of local therapy for BMs, no extracranial disease, LDH level of $<1.5$ times the upper limit of normal, a neutrophil-to-lymphocyte ratio (NLR) of less than 5.0 (11-13), an RPA class of 2 or less, and a GPA score of 1.5 or more. In the multivariate analyses, better survival was independently associated with PD-L1 expression, no history of local therapy for BMs, no extracranial disease, and an NLR of less than 5.0 (Figure 2).

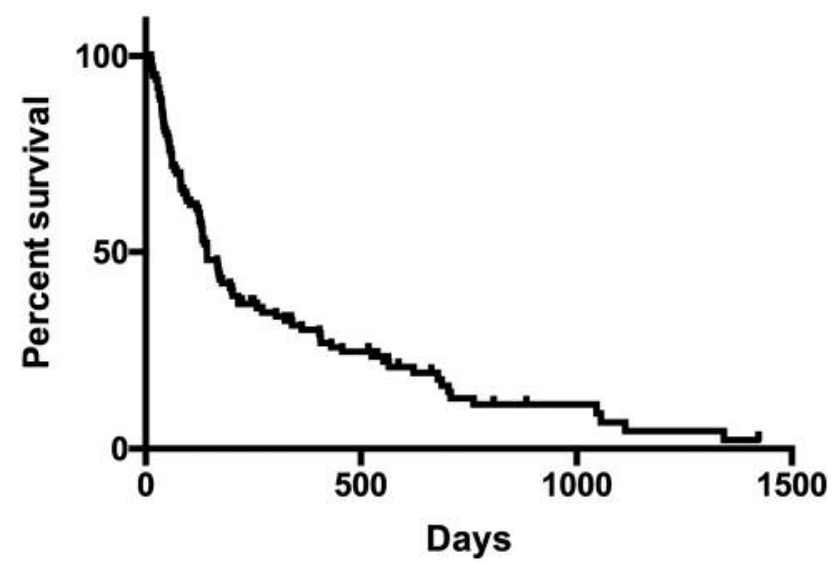

Figure 1. Overall survival after whole-brain radiotherapy. The median survival interval was 143 days, and the 1-year survival rate was $30.4 \%$.

\section{Discussion}

There are various applications for using WBRT to treat BMs, such as with/without surgical resection or radiosurgery, or as palliative treatment for patients with a poor prognosis. Immune checkpoint inhibitors have also been dramatically changing the modern treatment options for metastases, with a clear survival benefit among patients with metastatic NSCLC (7, 8). Moreover, local radiotherapy reportedly improves the immune response to metastatic tumors (9). Thus, radiotherapy can help improve palliative care and also enhance the immune response to systemic disease in combination with immune therapy. The recent KEYNOTE001 trial also revealed favorable outcomes among patients who had previously received radiotherapy (10). Although there is a lack of prognostic data for predicting the potential immune response among patients who receive WBRT for NSCLC, our finding may help support a shift in the current paradigm of immune therapy and radiotherapy.

Activated T-cells can be suppressed by marked neutrophil infiltration, and a high NLR may reduce the effects of the lymphocyte-mediated cellular immune response, which could promote cancer progression $(11,14)$. In addition, the pretreatment NLR among patients with NSCLC has been prospectively shown to be negatively correlated with prognosis (12). Furthermore, a previous report indicated that the NLR might predict the effects of immune checkpoint inhibitors in patients with NSCLC (13). However, there are limited data regarding the use of NLR to predict the response of patients with NSCLC to WBRT. To the best of our knowledge, this is the first study to indicate that patients with a low NLR may experience prolonged survival after WBRT for advanced NSCLC, which highlights a potential immune-mediated response in 
Table I. Patient clinicopathological characteristics $(n=100)$.

\begin{tabular}{|c|c|c|}
\hline & & Value \\
\hline Age, years & Median (range) & $67(29-83)$ \\
\hline \multirow[t]{2}{*}{ Gender, n (\%) } & Male & $62(62)$ \\
\hline & Female & $38(38)$ \\
\hline Smoking, pack-years & Median (range) & $20(0-162)$ \\
\hline \multirow[t]{5}{*}{ ECOG-PS, n (\%) } & 0 & $18(18)$ \\
\hline & 1 & $49(49)$ \\
\hline & 2 & $23(23)$ \\
\hline & 3 & $9(9)$ \\
\hline & 4 & $1(1)$ \\
\hline \multirow[t]{3}{*}{ Pathological type, n (\%) } & Adenocarcinoma & $82(82)$ \\
\hline & Squamous cell carcinoma & $12(12)$ \\
\hline & Other & $6(6)$ \\
\hline \multirow[t]{3}{*}{ EGFR mutation, $\mathrm{n}(\%)$} & Positive & $46(46)$ \\
\hline & Negative & $42(42)$ \\
\hline & Unknown & $12(12)$ \\
\hline \multirow[t]{3}{*}{$A L K$ rearrangement, $\mathrm{n}(\%)$} & Positive & $7(7)$ \\
\hline & Negative & $69(69)$ \\
\hline & Unknown & $24(24)$ \\
\hline \multirow[t]{3}{*}{ PD-L1 status, n (\%) } & Positive & $7(7)$ \\
\hline & Negative & $5(5)$ \\
\hline & Unknown & $88(88)$ \\
\hline \multirow[t]{4}{*}{ Anti-PD-1 therapy, n (\%) } & Yes & $22(22)$ \\
\hline & Before WBRT & $10(45)$ \\
\hline & After WBRT & $12(55)$ \\
\hline & No & $78(78)$ \\
\hline Days from diagnosis to first appearance of $\mathrm{BMs}^{\dagger}$ & Median (range) & $175(0-4,236)$ \\
\hline \multirow[t]{5}{*}{ History of local treatment for BMs, $\mathrm{n}(\%)^{\S}$} & Yes & $24(100)$ \\
\hline & SRS & $18(75)$ \\
\hline & Surgery & $3(13)$ \\
\hline & SRS and surgery & $3(13)$ \\
\hline & No & 76 \\
\hline Maximum diameter of $\mathrm{BMs}, \mathrm{mm}$ & Median (range) & $15(6-55)$ \\
\hline \multirow[t]{6}{*}{ Number of BMs, n (\%) } & 1 & $8(8)$ \\
\hline & 2 & $10(10)$ \\
\hline & 3 & $9(9)$ \\
\hline & 4 & $5(5)$ \\
\hline & 5 & $9(9)$ \\
\hline & $\geq 6$ & $59(59)$ \\
\hline Total prescribed dose in Gy & Median (range) & $30(15-45)$ \\
\hline Number of fractions & Median (range) & $10(5-18)$ \\
\hline BED10 in Gy & Median (range) & $39(19.5-56.3)$ \\
\hline \multirow[t]{3}{*}{ RPA class, $\mathrm{n}(\%)$} & 1 & $2(2)$ \\
\hline & 2 & $74(74)$ \\
\hline & 3 & $24(24)$ \\
\hline \multirow[t]{7}{*}{ GPA score, n (\%) } & 0 & $18(18)$ \\
\hline & 0.5 & $22(22)$ \\
\hline & 1.0 & $30(30)$ \\
\hline & 1.5 & $18(18)$ \\
\hline & 2.0 & $8(8)$ \\
\hline & 2.5 & $3(3)$ \\
\hline & 3.5 & $1(1)$ \\
\hline
\end{tabular}

ECOG-PS, Eastern Cooperative Oncology Group performance status; EGFR, epidermal growth factor receptor gene; $A L K$, anaplastic lymphoma kinase gene; PD-L1, programmed death-ligand 1; PD-1, programmed death-1; BMs, brain metastases; SRS, stereotactic radiosurgery; BED, biologically effective dose; RPA, Radiation Therapy Oncology Group-recursive partitioning analysis; GPA, graded prognostic assessment. ${ }^{\dagger}$ BMs at initial diagnosis were considered detected on day 0. ${ }^{\S}$ Local treatment included SRS and surgical resection. 
Table II. Factors affecting overall survival.

\begin{tabular}{|c|c|c|c|c|c|c|}
\hline \multirow[b]{2}{*}{ Factor } & \multirow[b]{2}{*}{$\begin{array}{l}\text { Patients } \\
(\mathrm{n}=100)\end{array}$} & \multirow[b]{2}{*}{$\begin{array}{c}\text { 1-Year survival } \\
(\%)\end{array}$} & \multicolumn{2}{|c|}{ Univariate analysis } & \multicolumn{2}{|c|}{ Multivariate analysis } \\
\hline & & & $\operatorname{HR}(95 \% \mathrm{CI})$ & $p$-Value & $\operatorname{HR}(95 \% \mathrm{CI})$ & $p$-Value \\
\hline \multicolumn{7}{|l|}{ Age } \\
\hline$<65$ Years & 38 & 28.5 & 1 & & & \\
\hline$\geq 65$ Years & 62 & 31.7 & $1.2377(0.8035-1.9365)$ & 0.3363 & & \\
\hline \multicolumn{7}{|l|}{ Gender } \\
\hline Male & 62 & 31.9 & 1 & & & \\
\hline Female & 38 & 29.0 & $0.9431(0.6056-1.4495)$ & 0.7914 & & \\
\hline \multicolumn{7}{|l|}{ ECOG-PS } \\
\hline $0-1$ & 66 & 36.6 & 1 & & 1 & \\
\hline$\geq 2$ & 34 & 18.2 & $2.4380(1.5178-3.8573)$ & 0.0003 & $1.3000(0.5061-2.9305)$ & 0.5617 \\
\hline \multicolumn{7}{|l|}{ Smoking, pack-years } \\
\hline$<30$ & 55 & 37.3 & 1 & & 1 & \\
\hline$\geq 30$ & 45 & 22.0 & $1.3537(0.8775-2.0771)$ & 0.1694 & $1.0667(0.5975-1.8799)$ & 0.8250 \\
\hline \multicolumn{7}{|l|}{ Pathological type } \\
\hline Adenocarcinoma & 82 & 33.8 & 1 & & 1 & \\
\hline Non-adenocarcinoma & 18 & 11.1 & $1.8271(1.0125-3.1126)$ & 0.0456 & $1.8319(0.9398-3.4146)$ & 0.0743 \\
\hline \multicolumn{7}{|c|}{ Clinical stage at initial diagnosis* } \\
\hline I-III & 34 & 28.9 & 1 & & & \\
\hline IV & 66 & 31.2 & $0.9239(0.5913-1.4765)$ & 0.7346 & & \\
\hline \multicolumn{7}{|l|}{ EGFR mutation } \\
\hline Negative/unknown & 54 & 31.3 & 1 & & & \\
\hline Positive & 46 & 29.7 & $0.8854(0.5704-1.3666)$ & 0.5829 & & \\
\hline \multicolumn{7}{|l|}{ ALK rearrangement } \\
\hline Negative/unknown & 93 & 31.9 & 1 & & & \\
\hline Positive & 7 & 0.0 & $1.2194(0.4700-2.6053)$ & 0.6526 & & \\
\hline \multicolumn{7}{|l|}{ PD-L1 status } \\
\hline Negative/unknown & 93 & 26.3 & 1 & & 1 & 0.0008 \\
\hline Positive & 7 & 85.7 & $0.0928(0.0053-0.4184)$ & 0.0002 & $0.0804(0.0044-0.4145)$ & \\
\hline \multicolumn{7}{|l|}{ Use of anti-PD-1 therapy } \\
\hline Yes & 22 & 40.9 & 1 & & 1 & \\
\hline No & 78 & 27.5 & $1.6789(0.9900-3.0295)$ & 0.0547 & $1.1322(0.6028-2.2370)$ & 0.7073 \\
\hline \multicolumn{7}{|c|}{ Presence of BMs at initial diagnosis } \\
\hline Yes & 40 & 37.2 & 1 & 0.2009 & & \\
\hline No & 60 & 25.8 & $1.3316(0.8598-2.0913)$ & & & \\
\hline \multicolumn{7}{|c|}{ History of local treatment for $\mathrm{BMs}^{\S}$} \\
\hline Yes & 24 & 12.5 & 1 & & 1 & \\
\hline No & 76 & 36.0 & $0.4193(0.2623-0.6911)$ & 0.0009 & $0.4464(0.2556-0.7933)$ & 0.0065 \\
\hline \multicolumn{7}{|l|}{$\begin{array}{l}\text { Initial diagnosis to first } \\
\text { appearance of } \mathrm{BMs}^{\dagger}\end{array}$} \\
\hline$<175$ Days & 49 & 32.4 & 1 & & & \\
\hline$\geq 175$ Days & 51 & 28.3 & $1.0123(0.6570-1.5602)$ & 0.9557 & & \\
\hline Symptoms due to BMs & & & & & & \\
\hline Yes & 66 & 31.3 & 1 & & & \\
\hline No & 34 & 28.5 & $0.7899(0.4895-1.2418)$ & 0.3120 & & \\
\hline Maximum diameter of $\mathrm{F}$ & & & & & & \\
\hline$<3 \mathrm{~cm}$ & 78 & 31.5 & 1 & & & \\
\hline$\geq 3 \mathrm{~cm}$ & 22 & 26.5 & $1.3726(0.8160-2.2183)$ & 0.2242 & & \\
\hline Number of BMs & & & & & & \\
\hline$\leq 3$ & 27 & 29.6 & 1 & & & \\
\hline$>3$ & 73 & 30.6 & $1.0794(0.6798-1.7762)$ & 0.7527 & & \\
\hline Presence of extracranial & & & & & & \\
\hline Yes & 94 & 26.1 & 1 & & 1 & \\
\hline No & 6 & 100.0 & $0.1824(0.0300-0.5814)$ & 0.0015 & $0.2271(0.0360-0.7812)$ & 0.0151 \\
\hline Radiotherapeutic dose & & & & & & \\
\hline$<40 \mathrm{~Gy}$ & 58 & 27.3 & 1 & & 1 & \\
\hline$\geq 40 \mathrm{~Gy}$ & 42 & 34.6 & $0.7064(0.4548-1.0839)$ & 0.1121 & $1.0947(0.6568-1.8185)$ & 0.7270 \\
\hline
\end{tabular}




\begin{tabular}{|c|c|c|c|c|c|c|}
\hline \multirow[b]{2}{*}{ Factor } & \multirow[b]{2}{*}{$\begin{array}{l}\text { Patients } \\
(\mathrm{n}=100)\end{array}$} & \multirow[b]{2}{*}{$\begin{array}{c}\text { 1-Year survival } \\
(\%)\end{array}$} & \multicolumn{2}{|c|}{ Univariate analysis } & \multicolumn{2}{|c|}{ Multivariate analysis } \\
\hline & & & $\mathrm{HR}(95 \% \mathrm{CI})$ & $p$-Value & $\operatorname{HR}(95 \% \mathrm{CI})$ & $p$-Value \\
\hline \multicolumn{7}{|l|}{ LDH } \\
\hline$<1.5 \times \mathrm{ULN}$ & 75 & 33.7 & 1 & & 1 & \\
\hline$\geq 1.5 \times \mathrm{ULN}$ & 25 & 20.0 & $1.6595(1.0106-2.6415)$ & 0.0455 & $1.6156(0.9055-2.7995)$ & 0.1025 \\
\hline \multicolumn{7}{|l|}{ NLR } \\
\hline$<5.0$ & 58 & 42.4 & 1 & & 1 & \\
\hline$\geq 5.0$ & 42 & 13.9 & $2.1441(1.3548-3.3781)$ & 0.0013 & $2.5560(1.4420-4.5628)$ & 0.0013 \\
\hline \multicolumn{7}{|l|}{ RPA class } \\
\hline$\leq 2$ & 76 & 34.6 & 1 & & 1 & \\
\hline 3 & 24 & 16.7 & $2.6366(1.5795-4.2642)$ & 0.0004 & $1.7052(0.6784-4.7117)$ & 0.2629 \\
\hline \multicolumn{7}{|l|}{ GPA score } \\
\hline$<1.5$ & 70 & 25.1 & 1 & & 1 & \\
\hline$\geq 1.5$ & 30 & 42.9 & $0.4443(0.2649-0.7174)$ & 0.0007 & $0.5880(0.3303-1.0233)$ & 0.0604 \\
\hline
\end{tabular}

HR, Hazard ratio; CI, confidence interval; ECOG-PS, Eastern Cooperative Oncology Group performance status; EGFR, epidermal growth factor receptor gene; $A L K$, anaplastic lymphoma kinase gene; PD-L1, programmed death-ligand 1; PD-1, programmed death-1; BMs, brain metastases; BED, biologically-effective dose; LDH, lactate dehydrogenase; ULN, upper limit of normal; NLR, neutrophil-to-lymphocyte ratio; RPA, Radiation Therapy Oncology Group-recursive partitioning analysis; GPA, graded prognostic assessment. ${ }^{\dagger}$ BMs at the initial diagnosis were considered detected on day $0 . *$ Seventh version of the American Joint Committee on Cancer/International Union for Cancer Control TNM staging system. ${ }^{\circledR}$ Local treatment included stereotactic radiosurgery and surgical resection.
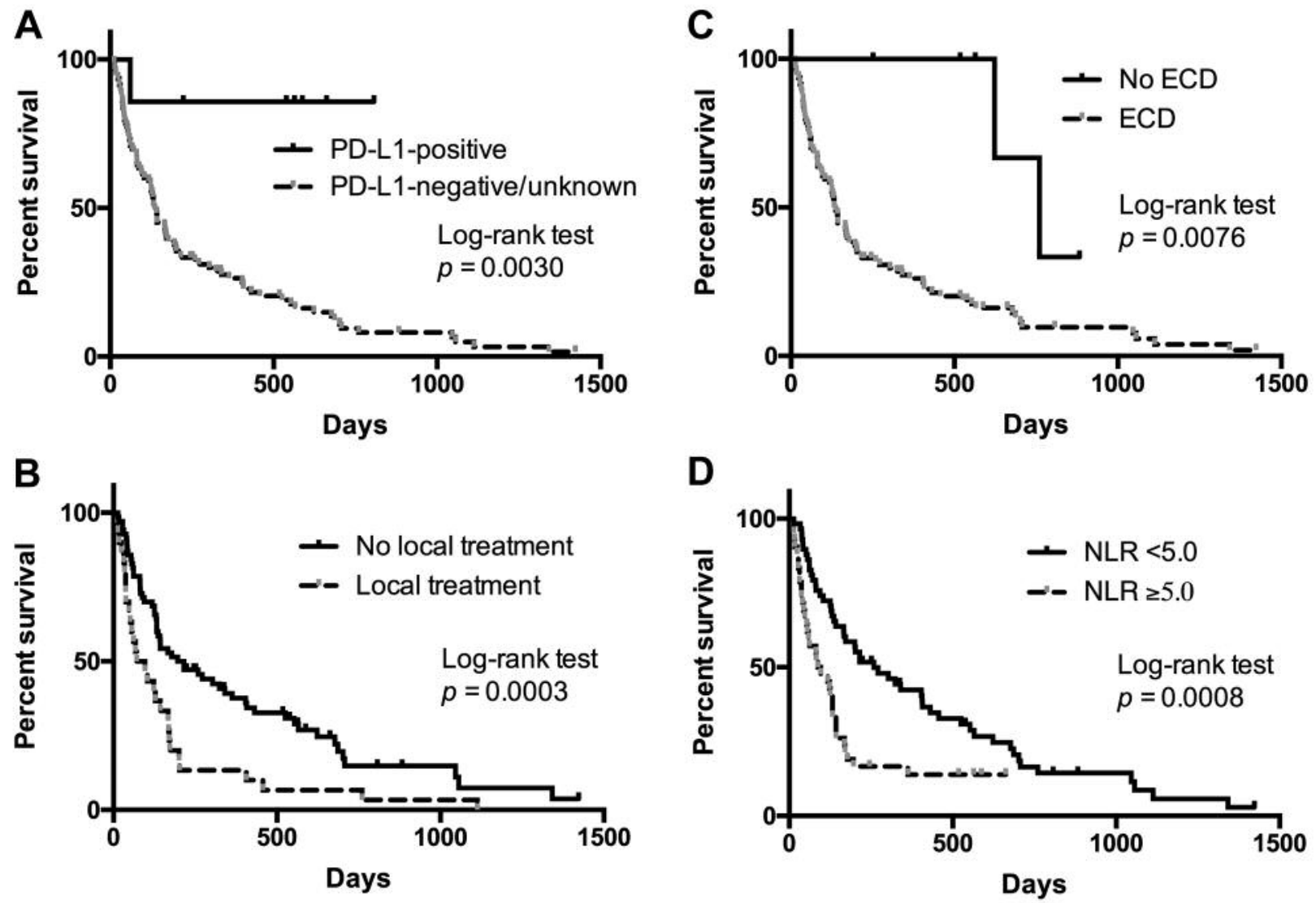

Figure 2. Overall survival according to predictors. Overall survival curves are shown for predictors that were significant in the univariate and multivariate analyses: programmed death-ligand 1 (PD-L1) expression status in the biopsy specimens $(A)$, history of local interventions including stereotactic radiosurgery and surgery $(B)$, extracranial disease $(E C D)$ status $(C)$, and serum neutrophil-to-lymphocyte ratio $(N L R)(D)$. 
this patient population. Therefore, we speculate that the pre-treatment NLR can help identify patients with BM who should receive WBRT.

Our univariate and multivariate analyses revealed that better survival was associated with PD-L1 expression, no history of local therapy (SRS/surgery) for BMs, and no extracranial disease. Epidermal growth factor receptor $(E G F R)$ mutation- and anaplastic lymphoma kinase $(A L K)$ rearrangement-positive status were not apparently associated with survival. However, the applicability of these gene statuses and PD-L1 expression to WBRT remains controversial. Most previous reports have indicated that EGFR mutation and $A L K$ rearrangement predict good survival among patients with BMs (15). Robin et al. reported favorable outcomes after SRS for multiple metastases in patients with EGFR- and $A L K$-driven NSCLC in their relatively small retrospective study (4). We failed to detect a significant role for $E G F R$ and $A L K$ status when we examined WBRT in a similar population. While a meta-analysis of more than 10,000 patients with NSCLC by Zhang et al. indicated that PD-L1 expression was correlated with poor prognosis (16), their data included a large variety of patient backgrounds and disease stages in comparison with our study, where the cohort was more uniform with all eligible patients being diagnosed with BMs. Further prospective studies are needed to determine whether WBRT, targeted therapy, SRT, and/or SRS are preferable for patients with EGFR-, ALK-, and PD-L1- positive BMs.

The present study has several limitations, including its retrospective design, relatively small sample size, and heterogeneous patient characteristics. We included a small number of PD-L1-positive patients $(n=7)$, including six patients who received anti-PD-1 therapy, which was associated with improved survival in the univariate analysis, but not in the multivariate analysis. In this context, patients with PD-L1-positive metastatic lung cancer are likely to receive immune checkpoint inhibitors, which could improve their survival with advanced $\operatorname{NSCLC}(7,8)$. These factors may have biased our findings based on the benefits of antiPD-1 therapy.

\section{Conclusion}

The present study revealed that an NLR of less than 5.0 and PD-L1 expression significantly predicted improved survival after WBRT for BMs from NSCLC. Prolonged survival from the start of WBRT was associated with low NLR, revealing a potent strong immune response in such patients. Since these patients may be eligible to receive WBRT plus immune checkpoint inhibitors, the potential strong immune response might result in better survival outcomes. Nevertheless, a prospective trial with a large homogeneous patient sample is needed to validate our findings.

\section{Acknowledgements}

This work was supported by a Grant-in-Aid for Young Scientists (B) Grant Number 17K16493. The Authors would like to acknowledge Editage (www.editage.jp) for language editing.

\section{References}

1 Barnholtz-Sloan JS, Sloan AE, Davis FG, Vigneau FD, Lai P and Sawaya RE: Incidence proportions of brain metastases in patients diagnosed (1973 to 2001) in the Metropolitan Detroit Cancer Surveillance System. J Clin Oncol 22: 2865-2872, 2004.

2 Gaspar L, Scott C, Rotman M, Asbell S, Phillips T, Wasserman T, McKenna WG, and Byhardt R: Recursive partitioning analysis (RPA) of prognostic factors in three Radiation Therapy Oncology Group (RTOG) brain metastases trials. Int J Radiat Oncol Biol Phys 37: 745-751, 1997.

3 Sperduto PW, Berkey B, Gaspar LE, Mehta M and Curran W: A new prognostic index and comparison to three other indices for patients with brain metastases: an analysis of 1,960 patients in the RTOG database. Int J Radiat Oncol Biol Phys 70: 510-514, 2018.

4 Robin TP, Camidge DR, Stuhr K, Nath SK, Breeze RE, Pacheco JM, Liu AK, Gaspar LE, Purcell WT, Doebele RC, Kavanagh BD and Rusthoven CG: Excellent outcomes with radiosurgery for multiple brain metastases in ALK and EGFR driven non-small cell lung cancer. J Thorac Oncol 13: 715-720, 2018.

5 Tsao MN, Rades D, Wirth A, Lo SS, Danielson BL, Gaspar LE, Sperduto PW, Vogelbaum MA, Radawski JD, Wang JZ, Gillin MT, Mohideen N, Hahn CA and Chang EL: Radiotherapeutic and surgical management for newly diagnosed brain metastasis(es): An American Society for Radiation Oncology evidence-based guideline. Pract Radiat Oncol 2: 210-225, 2012.

6 Mulvenna P, Nankivell M, Barton R, Faivre-Finn C, Wilson P, McColl E, Moore B, Brisbane I, Ardron D, Holt T, Morgan S, Lee C, Waite K, Bayman N, Pugh C, Sydes B, Stephens R, Parmar MK and Langley RE: Dexamethasone and supportive care with or without whole-brain radiotherapy in treating patients with non-small cell lung cancer with brain metastases unsuitable for resection or stereotactic radiotherapy (QUARTZ): results from a phase 3, non-inferiority, randomised trial. Lancet 388: 2004-2014, 2016.

7 Borghaei H, Paz-Ares L, Horn L, Spigel DR, Steins M, Ready NE, Chow LQ, Vokes EE, Felip E, Holgado E, Barlesi F, Kohlhäufl M, Arrieta $\mathrm{O}$, Burgio MA, Fayette J, Lena H, Poddubskaya E, Gerber DE, Gettinger SN, Rudin CM, Rizvi N, Crinò L, Blumenschein GR Jr., Antonia SJ, Dorange C, Harbison CT, Graf Finckenstein F and Brahmer JR: Nivolumab versus docetaxel in advanced nonsquamous non-small-cell lung cancer. N Engl J Med 373: 1627-1639, 2015.

8 Brahmer J, Reckamp KL, Baas P, Crinò L, Eberhardt WE, Poddubskaya E, Antonia S, Pluzanski A, Vokes EE, Holgado E, Waterhouse D, Ready N, Gainor J, Arén Frontera O, Havel L, Steins M, Garassino MC, Aerts JG, Domine M, Paz-Ares L, Reck M, Baudelet C, Harbison CT, Lestini B and Spigel DR: Nivolumab versus docetaxel in advanced squamous-cell nonsmall-cell lung cancer. N Engl J Med 373: 123-135, 2015. 
9 Twyman-Saint Victor C, Rech AJ, Maity A, Rengan R, Pauken KE, Stelekati E, Benci JL, Xu B, Dada H, Odorizzi PM, Herati RS, Mansfield KD, Patsch D, Amaravadi RK, Schuchter LM, Ishwaran H, Mick R, Pryma DA, Xu X, Feldman MD, Gangadhar TC, Hahn SM, Wherry EJ, Vonderheide RH and Minn AJ: Radiation and dual checkpoint blockade activate nonredundant immune mechanisms in cancer. Nature 520: 373-377, 2015.

10 Shaverdian N, Lisberg AE, Bornazyan K, Veruttipong D, Goldman JW, Formenti SC, Garon EB and Lee P: Previous radiotherapy and the clinical activity and toxicity of pembrolizumab in the treatment of non-small-cell lung cancer: A secondary analysis of the KEYNOTE-001 phase 1 trial. Lancet Oncol 18: 895-903, 2017.

11 Diakos CI, Charles KA, McMillan DC and Clarke SJ: Cancerrelated inflammation and treatment effectiveness. Lancet Oncol 15: e493-503, 2014.

12 Pinato DJ, Shiner RJ, Seckl MJ, Stebbing J, Sharma R and Mauri FA: Prognostic performance of inflammation-based prognostic indices in primary operable non-small cell lung cancer. Br J Cancer 110: 1930-1935, 2014.
13 Diem S, Schmid S, Krapf M, Flatz L, Born D, Jochum W, Templeton AJ and Früh M: Neutrophil-to-Lymphocyte ratio (NLR) and platelet-to-lymphocyte ratio (PLR) as prognostic markers in patients with non-small cell lung cancer (NSCLC) treated with nivolumab. Lung Cancer 111: 176-181, 2017.

14 Shau HY and Kim A: Suppression of lymphokine-activated killer induction by neutrophils. J Immunol 141: 4395-4402, 1988.

15 Baik CS, Chamberlain MC and Chow LQ: Targeted therapy for brain metastases in EGFR-mutated and $A L K$-rearranged nonsmall-cell lung cancer. J Thorac Oncol 10: 1268-1278, 2015.

16 Zhang M, Li G, Wang Y, Wang Y, Zhao S, Haihong P, Zhao H and Wang Y: PD-L1 expression in lung cancer and its correlation with driver mutations: A meta-analysis. Sci Rep 7: 10255, 2017.

Received September 10, 2018

Revised October 4, 2018

Accepted October 8, 2018 